\title{
PACKAGE PLANNING OF AUTONOMOUS VEHICLE CONCEPTS
}

\author{
König, Adrian; \\ Telschow, Daniel; \\ Nicoletti, Lorenzo; \\ Lienkamp, Markus \\ Institute of Automotive Technology, Technical University of Munich
}

\begin{abstract}
Autonomous driving will not just change vehicles themselves, but also the entire concept of mobility. New business models and the expansion of individual mobility to new groups of society are merely examples of possible impact. In order to create optimal vehicles for new technologies right from the start, vehicle concept optimization helps to find suitable solutions from numerous possible variations. The package as part of a vehicle concept is currently focused on passenger cars with steering wheels and pedals. Therefore, a new method is needed to plan the package of driverless and autonomous vehicles. In this paper, we present a possible method that separates the vehicle into the interior and the front and rear wagon. This way, different seating layouts can be considered and evaluated in terms of package efficiency. In the results, we check the plausibility by rebuilding a current battery electric vehicle (BEV) and, by way of example, show the variation of the gear angle and different seating layouts, and the resulting package efficiency.
\end{abstract}

Keywords: Autonomous, package, Computer Aided Design (CAD), Design methodology, Simulation

\section{Contact:}

König, Adrian

Technical University of Munich

Mechanical Engineering, Institute of Automotive Technology

Germany

adrian.koenig@ftm.mw.tum.de

Cite this article: König, A., Telschow, D., Nicoletti, L., Lienkamp, M. (2021) 'Package Planning of Autonomous Vehicle Concepts', in Proceedings of the International Conference on Engineering Design (ICED21), Gothenburg, Sweden, 16-20 August 2021. DOI:10.1017/pds.2021.498 


\section{INTRODUCTION}

The megatrends digitization, autonomous driving, connectivity and electric mobility are currently forcing the automotive industry to rethink the car (Schiekofer, 2020, p. 50, Nicoletti et al., 2020). While electric vehicles are already part of most manufacturers' portfolios, the automation of the driving function is in its early stages. In comparison to aircrafts, ships and trains, which are already highly automated, complex traffic situations on the road prevent a similarly fast development of road vehicles (Trommer et al., 2016, p. VI). Nevertheless, the degree of automation is increasing as years go by, and more and more automated functions are being integrated in today's vehicles.

Autonomous driving will not just change vehicles themselves, but also the entire mobility concept, including business models and use cases (Xavier Mosquet et al., 2015, p. 22). Current passenger cars are developed for a user who is also the customer. For autonomous vehicles (AVs), the user (the passenger) and the customer (e.g. a mobility provider) need not be the same person.

In order to take the new boundary conditions of autonomous driving into account, the development process must be rethought. As part of the development, the packaging helps place all the components in the available space and check the feasibility of a vehicle concept. In this paper, we present a new method of calculating parts of the package in an early phase of development to find optimal solutions for this new technology.

\section{STATE OF THE ART}

In this chapter, we present new boundary conditions for developing AVs and point out the advantages of using concept design optimization for such new technologies. We also show current methods of package planning of passenger vehicles. At the end, we derive the research gap as motivation for the following method.

\subsection{Autonomous Vehicles}

Numerous authors are discussing the potentials of autonomous driving. Trommer (Trommer et al., 2016, p. VII) points out four categories of potential:

- $\quad$ Safety (less accidents)

- Energy efficiency and emissions (less fuel consumption due to eco-driving)

- Availability (individual mobility for e.g. people without driver license or physical constraints)

- $\quad$ Comfort (trip time can be used for other activities)

Wadud (Wadud et al., 2016, p. 2) states that automation does not improve energy consumption per se, but enables new methods and improvements such as eco driving or rightsizing to improve it. Thus, the extent of the improvement always depends not only on the automation but also on the environment, in which the vehicle is driving. Eco driving and all its potential depends, for example, on the surrounding traffic and not just on the quality of the algorithm.

Furthermore, automating the driving function alone will probably have only a minor impact on the mobility we know today. To improve the user experience including price, availability and comfort, autonomous driving has to go hand in hand with new business models (Trommer et al., 2016, pp. VIIVIII). In business models like autonomous ride or car sharing, a computer can permanently perform the driving task to allow the passengers to make activities and the vehicle to make empty trips to the customers. Removing the driver's seat also enables new seating layouts and interior concepts, because the regulations for a driver's workplace no longer need to be fulfilled.

In the scope of this paper, we assume that AVs will be electric, because disadvantages related to charging will be compensated by the computer as new driver (Wadud et al., 2016, p. 11), and the efficiency of auxiliary power users is greater for electric vehicles than for those with internal combustion engines (Gawron et al., 2018, p. 3251). Furthermore, there is a striving for zero-emission operation of vehicles in order to reduce local emissions.

\subsection{Concept Design Optimization}

The starting point for the development of a new car model is often the predecessor or a competitor car (Münster et al., 2016, p. 3688). When a new technology is introduced, it is difficult to use a previous model since the manufacturer developed it with different boundary conditions from old technologies. On the other hand, this offers new degrees of freedom and allows new, unconventional solutions 
(Tzivanopoulos et al., 2014, p. 670). To deal with the difficulties and new freedoms, the concept design optimization is a common method of helping engineers at this early stage of design (Kuchenbuch, 2012). It includes modelling, sizing and selection of components and their influence on the total vehicle properties.

Starting with a vehicle equipped with an internal combustion engine, for example, engineers can barely find room for an electric battery, because the replaced fuel tank is much smaller. On the other hand, the engine compartment is oversized since the electric machine is smaller than a combustion engine. An electric vehicle developed in this way is called conversion design. The Volkswagen eGolf is one typical example of this type (Table 1 right) and is based on the version with a combustion engine.

If engineers develop a vehicle from scratch based on a new technology, they can consider important boundary conditions and profit from its advantages right from the start. This type of development is called purpose design. Some authors (Matz, 2015; Kuchenbuch, 2012) have already developed methods for an optimal purpose design of fully-electric vehicle concepts. The Volkswagen ID3 is, in comparison to the eGolf, a good example of purpose design. In comparison to the eGolf, the ID3 reaches a higher wheelbase at a similar length, which results in greater interior space. Furthermore, by increasing the vehicle height by only $5 \%$, the ID3 reaches a $38 \%$ higher battery capacity.

Table 1. Comparison between conversion and purpose design using the example of electrification

\begin{tabular}{|l|c|c|}
\hline Name & Volkswagen ID3 & Volkswagen eGolf \\
\hline Powertrain and battery & \\
& & \\
& & \\
Design type & Purpose design & Conversion design \\
\hline Length in mm & 4261 & 4270 \\
\hline Width in $\mathrm{mm}$ & 1809 & 1799 \\
\hline Height in $\mathrm{mm}$ & 1568 & 1482 \\
\hline Wheelbase in mm & 2771 & 2629 \\
\hline Trunk volume in liters & 385 & 380 \\
\hline Battery capacity in $\mathrm{kWh}$ & 58 & 36 \\
\hline
\end{tabular}

The electrification described above is one new technology that significantly changes the vehicle for the first time in decades. Besides electrification, automation as a second new technology will change the vehicle, as we know it today. To profit from this new technology as well, the authors develop a suitable purpose design for AVs (König et al., 2019). This method should help engineers avoid late changes and numerous iteration loops, which can lead to high costs and further changes (Lindemann $e t$ al., 2009, p. 1).

\subsection{Package Development for Passenger Vehicles}

One part of the concept design is selecting and sizing components to fulfil properties that have been defined at the beginning of the development process. The result is the vehicle package, which defines for example, the exterior dimensions, position and size of every component (Pischinger and Seiffert, 2016, p. 141). Common methods of describing important package dimensions include standards like the SAE J1100 or ISO 4131. These documents are intended to support engineers during the design of vehicles and help compare the geometries of different vehicles (Human Accom and Design Devices Stds Comm, 1973, p. 7). They define standardized dimensions of passenger cars and trucks, including both the exterior and the interior of the vehicle (Figure 1).

Associations like the Society of Automotive Engineers (SAE) established these standards in the 1970s and have hardly changed them since then. Their norms include a driver seat and thus many dimensions that are dependent on the position of the pedals and steering wheels. Conventional vehicles must comply with regulations relating to the driver's workplace. Because vehicles are designed symmetrically, the front-seat passenger in a conventional car is a driver seat without steering wheel and pedals. On the contrary, AVs without a driver can be optimally designed for passengers. 
Tzivanopoulus (2015) therefore defines the interior as a starting point for the development of AVs Accordingly, the exterior dimensions are an outcome of the interior.

Exterior dimensions

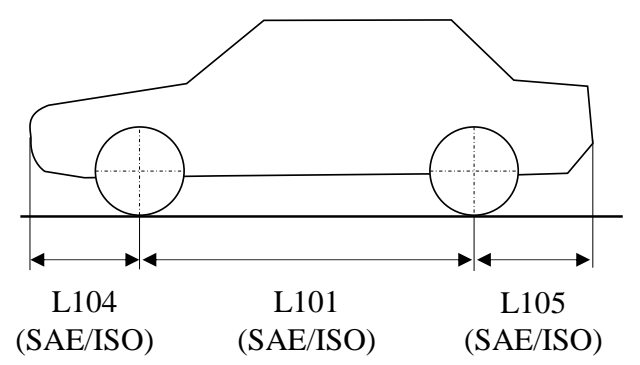

Interior dimensions

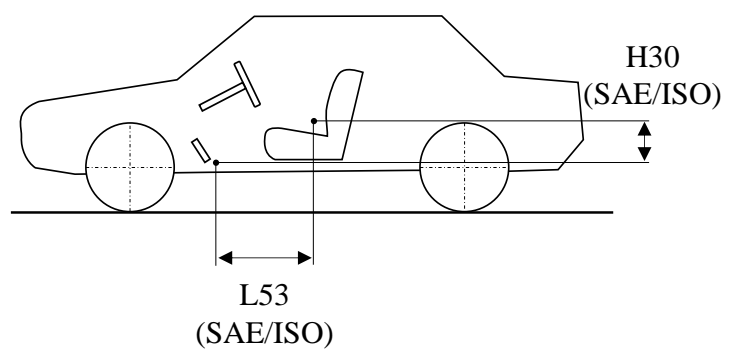

Figure 1: Examples for standardized exterior and interior dimensions of SAE J1100/ ISO 3141

Besides the conventional, two-rowed seating concepts with passengers facing in the direction of travel, concept designers are using three further seating concepts for most AVs (Table 2). The simplest modification is a single row with seats still facing the direction of travel. The vis-à-vis configuration enables easy communication between the passengers because they sit across from each other. A littleused solution is seats placed sideways. Table 2 lists some examples of concept cars and their seating concept. If two layouts are applicable for one vehicle, both are permanently or variably combined. The Mercedes F015, for example, has swivel seats that can be adjusted to a conventional or a vis-à-vis configuration.

Table 2. Seating layout for AV concepts

\begin{tabular}{|c|c|c|c|c|}
\hline Seating layout & Conventional & $\begin{array}{c}\text { Conventional } \\
\text { single row }\end{array}$ & Vis- á- vis & Sideways \\
\hline $\begin{array}{l}\text { Schematic sketch } \\
\rightarrow \text { Driving direction } \rightarrow\end{array}$ & & & & \\
\hline $\begin{array}{l}\text { Audi Aicon } \\
\text { (Audi AG, 2017) }\end{array}$ & $\mathrm{X}$ & & & \\
\hline $\begin{array}{l}\text { Google-Car } \\
\text { (Fairfield, 2016) }\end{array}$ & & $\mathrm{X}$ & & \\
\hline $\begin{array}{l}\text { Mercedes F015 } \\
\text { (Daimler AG, 2015) }\end{array}$ & $X$ & & $X$ & \\
\hline $\begin{array}{l}\text { Renault EZ-GO } \\
\text { (Groupe Renault, 2018) }\end{array}$ & & $\mathrm{X}$ & & $\mathrm{X}$ \\
\hline $\begin{array}{l}\text { Rolls-Royce 103 EX } \\
\text { (Rolls-Royce) }\end{array}$ & & $\bar{X}$ & & \\
\hline $\begin{array}{l}\text { Smart Vision EQ fortwo } \\
\text { (Daimler AG, 2020) }\end{array}$ & & $\mathrm{X}$ & & \\
\hline $\begin{array}{l}\text { Volkswagen Sedric } \\
\text { (Volkswagen, 2020a) }\end{array}$ & & & $X$ & \\
\hline $\begin{array}{l}\text { Volvo 360c } \\
\text { (Volvo Car, 2020) }\end{array}$ & & & $\mathrm{X}$ & \\
\hline
\end{tabular}

Apart from the version with seats placed sideways in the Renault, every concept is used by at least two or more vehicles. For all concepts except the conventional one, the norms above-mentioned are not applicable. 


\subsection{Research Gap}

Removing the driver's workplace gives designers and engineers new degrees of freedom in the vehicle design. To profit most from it, concept design optimization helps engineers to develop purposedesigned vehicles. One important part of the concept design optimization is the packaging of the car. Therefore, manufacturers are using standards like the SAE J1100 and the ISO 4131 to estimate interior and exterior dimensions of new models and to compare it with competitors. These norms are not applicable for most AVs, since they have new seating layouts and no steering wheel or pedals. New standards for AVs are to the knowledge of the authors not designed or published yet.

In this paper, the authors therefore present a new methodology to design the package of AVs and connect interior and exterior measurements. It includes several possible seating layouts with one or two rows to enable new freedoms in the design of future AVs.

\section{METHODOLOGY}

The interior plays a key role for AVs and is defined by the seating layout and the activities the passengers want to pursue. Despite the new interior, chassis and powertrain still have to meet similar requirements to conventional cars. They are placed in the front and rear wagon of the car. Therefore, the authors developed a methodology (Figure 2) to combine the flexibility in the design of the interior on the one hand and the existing models and dimensioning for the front and rear wagon on the other hand. Boundary surfaces (dotted section lines in Figure 2) help connect the different parts of the vehicle and enable their assembly. After the assembly, total vehicle measurements such as the length and width can be taken. The last step is iterative, because some input parameters for the calculation of the boundary surface are simultaneously output parameters of the assembly. As an example, on the one hand, the wheelbase is a necessary input for calculating the required steering angle. The steering angle is then used for the wheelhouse design inside the front boundary surface calculation. On the other hand, the wheelbase can be only measured after the interior and the front and rear wagon have been assembled.

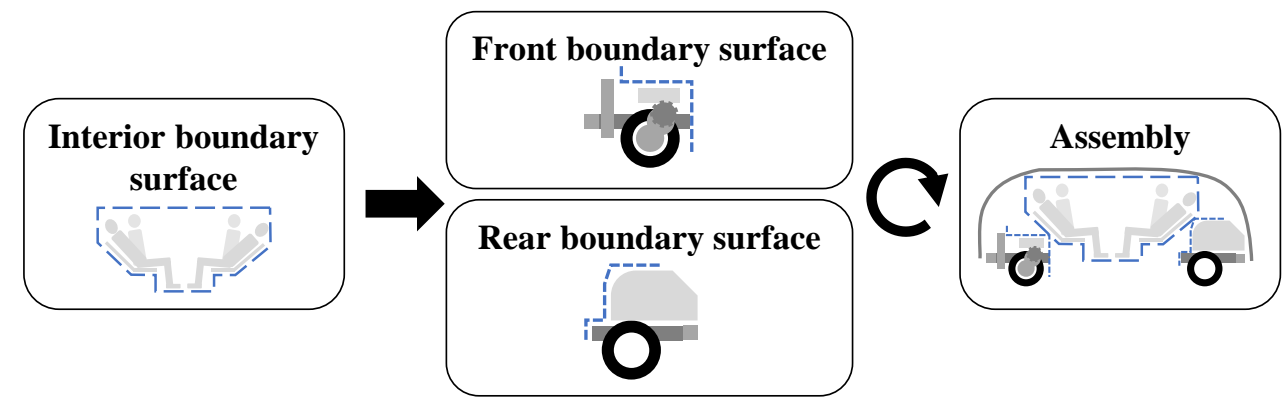

Figure 2. Process of package methodology for AVs

Models of every component help create the boundary surfaces. As mentioned above, the interior is the starting point of the design (Figure 3).

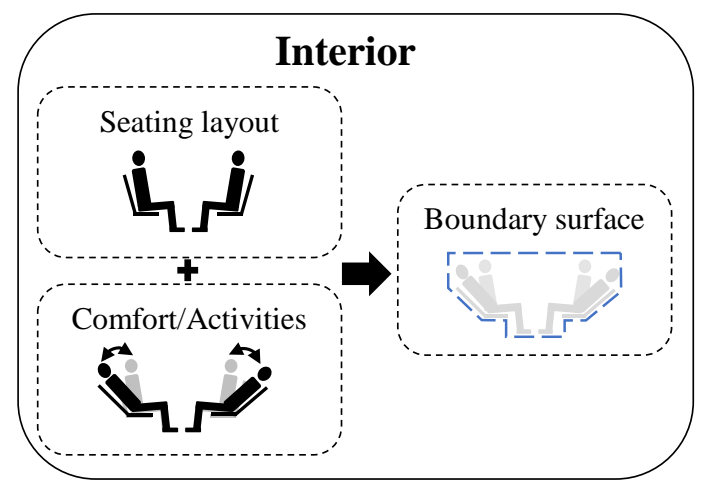

Default seating layouts:

\begin{tabular}{ll} 
Conventional \\
\hline Single row
\end{tabular}

Figure 3. Method to determine interior dimensions

The developer has to select one seat layout out of four default layouts. Although not part of Table 2, we added the back-to-back layout, since it enables an easy partitioning of the interior and thus supports ride 
sharing. By entering values like the backrest angle and legroom length, it is possible to calculate the space needed. In addition, possible comfort positions or activities like putting the seat in a sleeping position can be considered. Finally, the boundary surface of the interior is calculated.

To derive the exterior dimension from the interior, the authors develop a model to design the front and rear wagon (Figure 4). This model includes sub-models of the powertrain, wheelhouses, trunk and several other components like the cooler, which have partly already been published (Nicoletti et al., 2020).

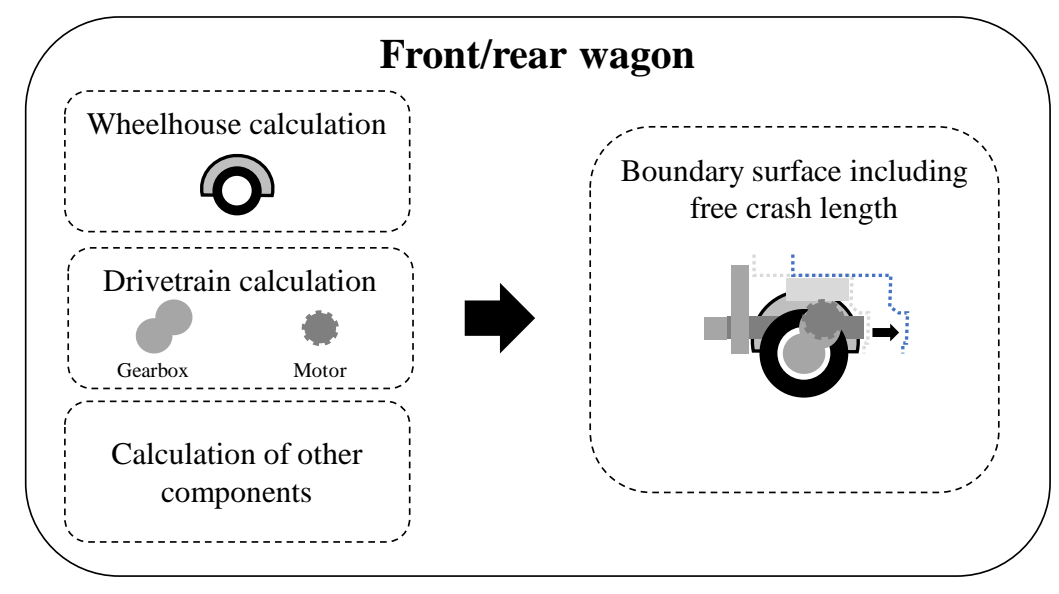

Figure 4. Method to determine front and rear wagon dimensions

The authors allow the user to choose different drivetrain topologies as well as several gear and motor types. This includes a front-, rear- or all-wheel drive, a coaxial or axis-parallel gearbox and an induction motor (IM) or a permanent-magnet synchronous motor (PMSM).

Besides housing powertrain components, the front and rear wagon serves to absorb energy in case of a crash. AVs that are integrated in the mixed traffic will need similar safety features as current vehicles. A parameter representative for passive safety is the free crash length, which is typically between $500 \mathrm{~mm}$ and $700 \mathrm{~mm}$ (Pischinger and Seiffert, 2016, p. 162). It describes the remaining length after nearly every non-deformable element (e.g. the motor and gearbox) has been pushed together into a block during a crash. Figure 5 shows an example with two block-building components. In a crash, the space between those components $\left(L_{1}\right.$ and $\left.L_{2}\right)$ is used for deformation. If the space is not sufficient to dissipate the crash energy $\left(L_{1}+L_{2}<L_{\text {tot }}\right)$, the block-building components are pushed into the interior with $\Delta \mathrm{L}$. In this case, the boundary surface has to be moved to the interior with $\Delta \mathrm{L}$ to avoid intrusion.
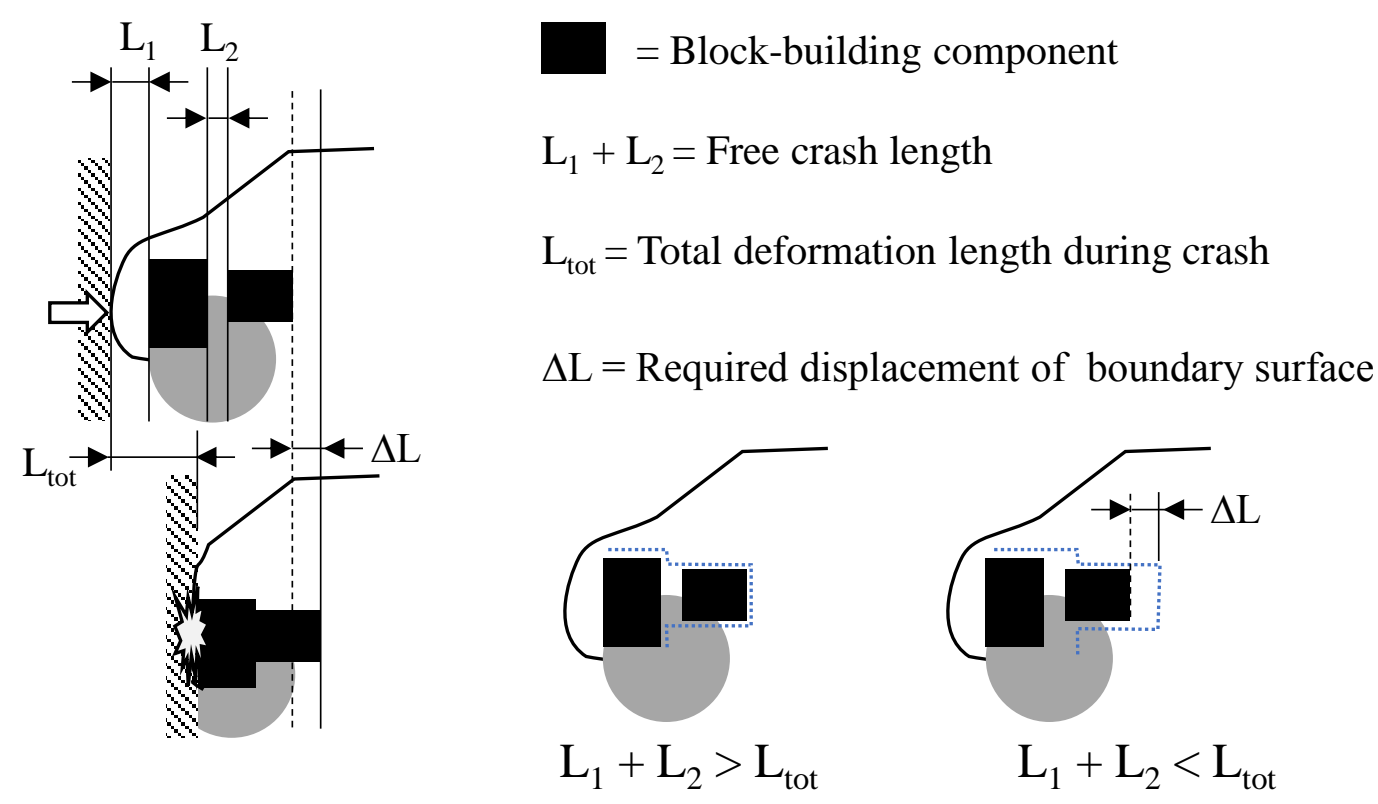

Figure 5. Movement of boundary surface due to free crash length 
If the user assumes a scenario where the traffic is made up of AVs alone and crashes are almost impossible, the deformation length $L_{t o t}$ can be set to zero. In this case, the package will be designed to be as dense as possible.

\section{RESULTS}

First, we rebuild an existing vehicle with our methodology to show that the following results are plausible. Second, we compare different seating layouts in terms of package efficiency. Lastly, by way of example, we show the influence of the free crash length on the vehicle length.

\subsection{Comparison with Current Method}

For a plausibility check we need already built AVs. Since only prototypes or concept cars with hardly any technical values are available, we use a conventional BEV to check the feasibility of the methodology in this paper. Even though we do not include any steering wheel or pedals, which are needed for conventional BEVs, we can define the seating position and the resulting position of the firewall.

We chose the Volkswagen ID.3 as an example for a purpose designed BEV. We use interior values and technical data (Volkswagen, 2020b) like the maximum range, acceleration time and measurements of the interior as input. Afterwards, we compare the result of our methodology with the actual car. Figure 6 shows a good match between the actual vehicle and the result of the tool.

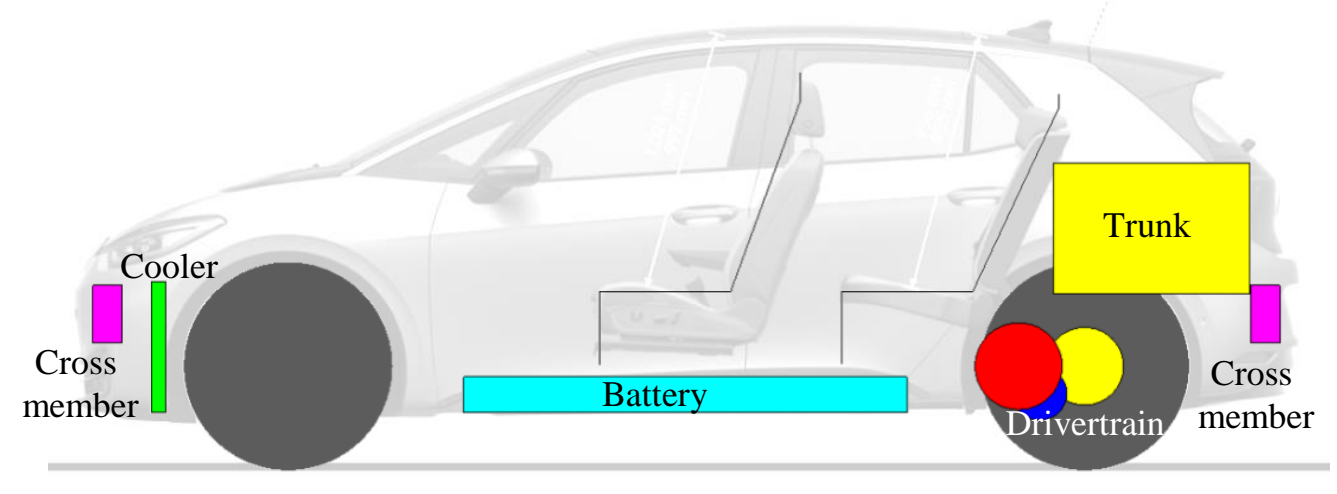

Figure 6. Comparison with current method using the Volkswagen ID.3 as an example

To calculation the powertrain, we used our longitudinal simulation (König et al., 2020 - 2020) and our tool for gear design, battery design and weight calculation, which will be published in the future. To calculate the package, we used the methodology shown in this paper and our wheelhouse design tool (Nicoletti et al., 2020).

\subsection{Comparison of Seating and Powertrain Layouts}

Different seating layouts are often discussed with a focus on the user benefits. We, on the other hand, will also evaluate the seating and powertrain layout in terms of package efficiency. This way, we can weigh fulfillment of user needs against efficiency of the complete vehicle. Since operating costs can also influence user satisfaction and are dependent on the vehicle package, the conflict that arises between costs and comfort can be evaluated with our methodology, too.

On the one hand, we evaluate the difference in package efficiency between different two-rowed seating layouts shown in Figure 6. On the other hand, we also vary the gear angle of a parallel oriented motor to show, by way of example, the influence of the powertrain layout. A gear angle of $90^{\circ}$ means that the motor is positioned above the gear, $0^{\circ}$ means the motor axle has the same z-coordinates as the drive shaft and is positioned between the gear and the battery. We keep interior dimensions like legroom or backrest angle and technical values like motor type or desired range constant and only changed the values mentioned. 


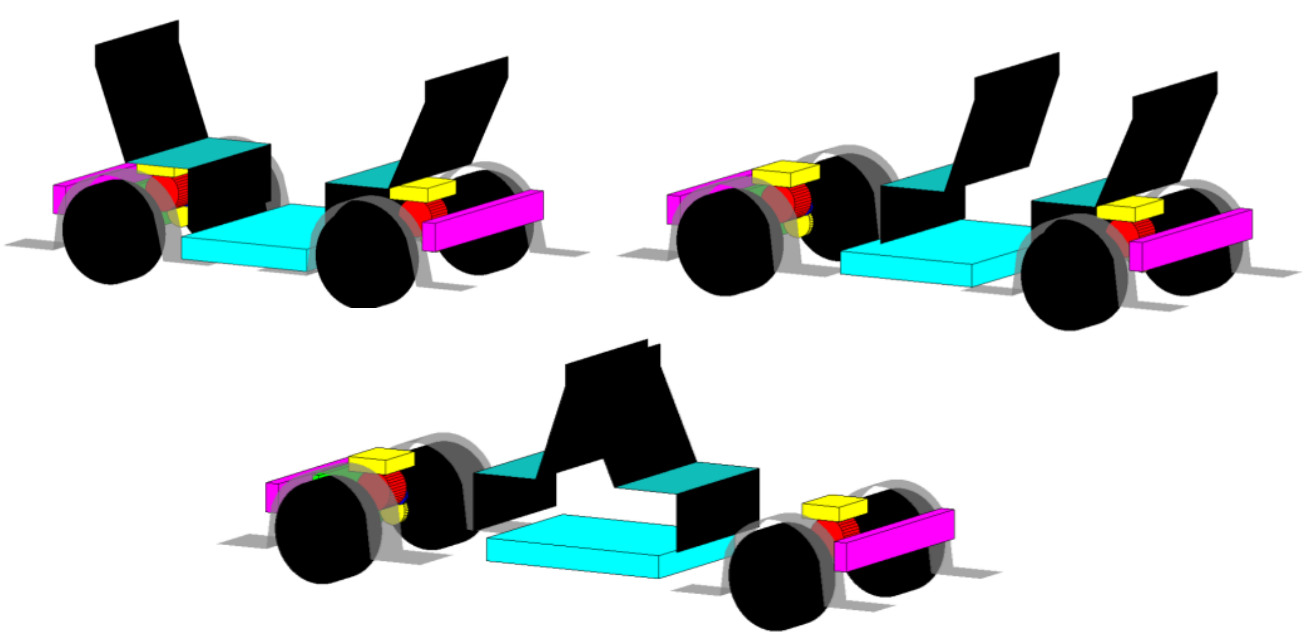

Figure 6. Different seating layouts: vis-à-vis (top left), conventional (top right), back-to-back (bottom)

We also suppose a free crash length of $0 \mathrm{~mm}$ to show the packages with highest efficiency. Table 3 shows the resulting vehicle length depending on the different configurations. We emphasize that these apply only for the chosen vehicle configuration and do not necessarily apply for other configurations.

Table 3. Comparison of seating layouts and their resulting vehicle length for different angle of axle parallel gear and different drivetrains

\begin{tabular}{|c|c|c|c|c|c|c|}
\hline Drivetrain & \multicolumn{2}{|c|}{ Front-wheel drive } & \multicolumn{2}{|c|}{ Rear-wheel drive } & \multicolumn{2}{|c|}{ All-wheel drive } \\
\hline Angle of gear & $90^{\circ}$ & $0^{\circ}$ & $90^{\circ}$ & $0^{\circ}$ & $90^{\circ}$ & $0^{\circ}$ \\
\hline $\begin{array}{c}\text { Vehicle length in mm } \\
\text { Vis-à-vis }\end{array}$ & 3,363 & $\mathbf{3 , 0 4 5}$ & 3,378 & $\mathbf{3 , 0 3 2}$ & $\mathbf{3 . 0 5 2}$ & $\mathbf{3 , 0 5 2}$ \\
\hline $\begin{array}{c}\text { Vehicle length in mm } \\
\text { Conventional }\end{array}$ & 3,741 & 3,741 & 4,042 & 3,737 & 3,728 & 3,728 \\
\hline $\begin{array}{c}\text { Vehicle length in mm } \\
\text { Back-to-back }\end{array}$ & 4,705 & 4,705 & 4,684 & 4,699 & 4,674 & 4,674 \\
\hline
\end{tabular}

The vis-à-vis layout, in this case, has the highest package efficiency. Only when the gear angle is $90^{\circ}$ can the seats not be positioned above the powertrain and the length increases. The conventional layout has similar values except for the rear-wheel drive with $90^{\circ}$ gear angle. In this case, the seats cannot be positioned over the powertrain, either. The reason, that this problem does not occur for both conventional and vis-à-vis layout using all-wheel drive, is a smaller motor and gear, since the same demand for performance is split between the two axles. The back-to-back layout is, in this case, the least efficient. The example shows that several factors can have an effect on the package efficiency. Results from other configurations, of course, will lead to different findings.

\subsection{Influence of Free Crash Length}

The crash length explained in Figure 5 is included in the package calculation. Block-building elements are currently powertrain components like the motor, gear and power electronics. Component twisting is not taken into account, because this depends on various factors and can only be determined by FEM-based crash simulations. We varied the minimal crash length for the vis-à-vis configuration (Figure 7, Table 4).

Even if no free crash length is required for the $0 \mathrm{~mm}$ configuration, a length of $90 \mathrm{~mm}$ is already available for deformation. This is caused by the placement of components, which are not considered as block building. Here, the wheelhouse causes distance between the interior and the front bumper and leads to the available $90 \mathrm{~mm}$. 


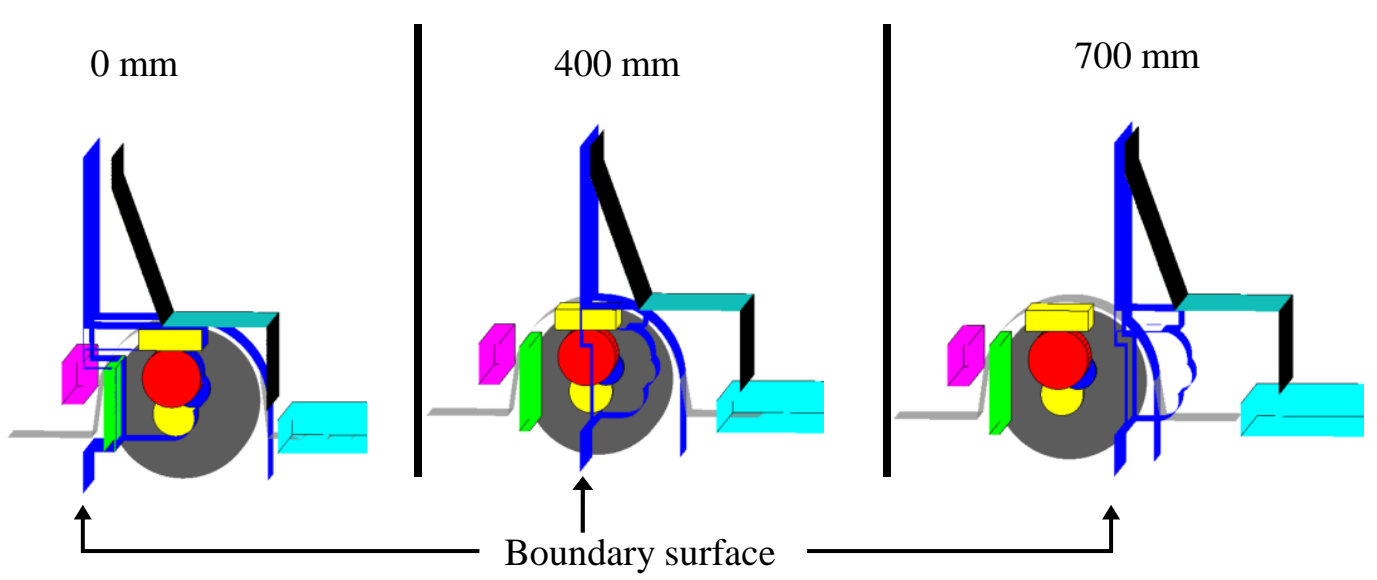

Figure 7. Movement of the boundary surface due to different required free crash lengths

Therefore, increasing the crash length to $400 \mathrm{~mm}$ does not increase the vehicle length by the same amount. Increasing the free crash length from $400 \mathrm{~mm}$ to $700 \mathrm{~mm}$ does, on the other hand, cause an increase in vehicle length by the same amount, because the free deformation space was already fully used by the $400 \mathrm{~mm}$ configuration.

Table 4. Change in vehicle length due to increased free crash length using the example of the vis-à-vis seating layout

\begin{tabular}{|c|c|c|c|}
\hline Required free crash length in $\mathrm{mm}$ & 0 & 400 & 700 \\
\hline Vehicle length in $\mathrm{mm}$ & 3,052 & 3,362 & 3,662 \\
\hline
\end{tabular}

\section{DISCUSSION AND OUTLOOK}

In this paper we presented a methodology for planning the package of AVs. We showed examples of potential results by varying parameters for selected configurations. We checked our package tool for plausibility by comparing the resulting package with the package of an existing vehicle. In the future, we will continue with more detailed models of e.g. the interior, trunk and axles and will further check the plausibility of the weight and technical data. We are currently only using components of the powertrain as block-building components that have an influence on the free crash length. Since further components are included in the front and rear wagon (e.g. the compressor of the HVAC-system), we will investigate whether they should also be considered block-building.

The results shown in chapter 4 apply only for the chosen vehicle configuration. Besides the varied parameters, others such as the wheel size, cell or machine type can also be varied. We are therefore working to implement an evolutionary algorithm to vary these parameters and find optimal solutions for selected sets of requirements. We will also continue to develop the interior model and differentiate between use cases (e.g. different seating positions and seats). The results can then be used to determine the potential of autonomous vehicles compared to conventional vehicles depending on their use case.

\section{ACKNOWLEDGMENTS}

This research by A.K. is accomplished within the project "UNICARagil" (FKZ EM2ADIS002). We acknowledge the financial support for the project from the Federal Ministry of Education and Research of Germany (BMBF). The author L.N. would like to thank the Technical University of Munich, which together AUDI AG sponsored his project.

\section{REFERENCES}

Audi AG (2017), “Audi Aicon concept car - autonomous on course for the future”, available at: https://www.audimediacenter.com/en/press-releases/audi-aicon-concept-car-autonomous-on-course-for-the-future-9332 (accessed 2 November 2020).

Daimler AG (2015), "Mercedes-Benz F 015 Luxury in Motion", available at: https://media.daimler.com/marsMediaSite/en/instance/ko/Overview-Mercedes-Benz-F-015-Luxury-inMotion.xhtml?oid=9904624 (accessed 2 November 2020). 
Daimler AG (2020), “Carsharing Anno 2030. Der smart vision EQ fortwo", available at: https://www.daimler.com/innovation/specials/iaa-2017/smart-vision-eq.html (accessed 2 November 2020).

Fairfield, N. (2016), "On the road with self-driving car user number one", available at: https://blog.waymo.com/2016/12/on-road-with-self-driving-car-user.html (accessed 2 November 2020).

Gawron, J.H., Keoleian, G.A., Kleine, R.D. de, Wallington, T.J. and Kim, H.C. (2018), "Life Cycle Assessment of Connected and Automated Vehicles. Sensing and Computing Subsystem and Vehicle Level Effects", Environmental science \& technology, Vol. 52 No. 5, pp. 3249-3256. 10.1021/acs.est.7b04576.

Groupe Renault (2018), “\#GENEVAMOTORSHOW2018 - RENAULT EZ-GO: A Vision of Shared Urban Mobility”, available at: https://group.renault.com/en/news-on-air/news/genevamotorshow2018-renault-ez-goa-vision-of-shared-urban-mobility/ (accessed 2 November 2020).

Human Accom and Design Devices Stds Comm (1973), SAE J1100: Motor Vehicle Dimensions REV 2009-11, SAE International, 400 Commonwealth Drive, Warrendale, PA, United States.

König, A., Nicoletti, L., Kalt, S., Muller, K., Koch, A. and Lienkamp, M. (2020 - 2020), “An Open-Source Modular Quasi-Static Longitudinal Simulation for Full Electric Vehicles", in 2020 Fifteenth International Conference on Ecological Vehicles and Renewable Energies (EVER), 9/10/2020 - 9/12/2020, Monte-Carlo, Monaco, IEEE, pp. 1-9. 10.1109/EVER48776.2020.9242981.

König, A., Schockenhoff, F., Koch, A. and Lienkamp, M. (2019), “Concept Design Optimization of Autonomous and Driverless Vehicles", paper presented at 8th International Conference on Power Science and Engineering, 2.-4. December, Dublin. 10.1109/ICPSE49633.2019.9041175.

Kuchenbuch, K. (2012), "Methodik zur Identifikation und zum Entwurf packageoptimierter Elektrofahrzeuge", Dissertation, Technical University of Braunschweig, 2012.

Lindemann, U., Maurer, M. and Braun, T. (2009), Structural Complexity Management: An Approach for the Field of Product Design, Springer Berlin Heidelberg, Berlin, Heidelberg. 10.1007/978-3-540-87889-6.

Matz, S. (2015), "Nutzerorientierte Fahrzeugkonzeptoptimierung in einer multimodalen Verkehrsumgebung”, Dissertation, Institute of Automotive Technology, Technical University of Munich, Munich, 2015.

Münster, M., Schäffer, M., Kopp, G., Kopp, G. and Friedrich, H.E. (2016), "New Approach for a Comprehensive Method for Urban Vehicle Concepts with Electric Powertrain and their Necessary Vehicle Structures", Transportation Research Procedia, Vol. 14, pp. 3686-3695. 10.1016/j.trpro.2016.05.487.

Nicoletti, L., Bronner, M., Danquah, B., Koch, A., Konig, A., Krapf, S., Pathak, A., Schockenhoff, F., Sethuraman, G., Wolff, S. and Lienkamp, M. (2020 - 2020), "Review of Trends and Potentials in the Vehicle Concept Development Process", in 2020 Fifteenth International Conference on Ecological Vehicles and Renewable Energies (EVER), 9/10/2020 - 9/12/2020, Monte-Carlo, Monaco, IEEE, pp. 1-15. 10.1109/EVER48776.2020.9243115.

Nicoletti, L., Romano, A., König, A., Schockenhoff, F. and Lienkamp, M. (2020), "Parametric Modeling of Mass and Volume Effects for Battery Electric Vehicles, with Focus on the Wheel Components", World Electric Vehicle Journal, Vol. 11 No. 4, p. 63. 10.3390/wevj11040063.

Pischinger, S. and Seiffert, U. (Eds.) (2016), Vieweg Handbuch Kraftfahrzeugtechnik, ATZ / MTZ-Fachbuch, 8., aktualisierte und erweiterte Auflage, Springer Vieweg, Wiesbaden. 10.1007/978-3-658-09528-4.

Rolls-Royce, "Rolls-Royce 103EX", available at: https://www.rolls-roycemotorcars.com/en_US/inspiringgreatness/vision/103ex.html (accessed 2 November 2020).

Schiekofer, P. (2020), "Development of a Technology Demonstrator for Autonomous and Electric Driving", ATZ Worldw, Vol. 122 No. 3, pp. 50-55. 10.1007/s38311-019-0192-2.

Trommer, S., Kolarova, V., Fraedrich, E., Kröger, L., Kickhöfer, B., Kuhnimhof, T., Lenz, B. and Phleps, P. (2016), Autonomous Driving: The Impact of Vehicle Automation on Mobility Behavior.

Tzivanopoulos, T., Stieg, J., Krasteva, P. and Vietor, T. (2014), "Analysis of new freedoms in future vehicle interiors", Stuttgart.

Tzivanopoulos, T., Watschke, H., Krasteva, P. and Vietor, T. (2015), "New Approaches iIn Vehicle Conception”, Auto Tech Review, Vol. 4 No. 10, pp. 28-33. 10.1365/s40112-015-1003-9.

Volkswagen (2020a), "Sedric concept car", available at: https://www.volkswagen-newsroom.com/en/sedricconcept-car-3552 (accessed 13 November 2020).

Volkswagen (2020b), "Volkswagen ID.3 1st. Technik und Preise”, available at: https://www.volkswagennewsroom.com/de/publikationen/preislisten/technik-und-preise-id-3-1st-ausgabetag-21-07-2020390/download.

Volvo Car (2020), “A new way to travel. The future is electric, autonomous and connected", available at: https://www.volvocars.com/intl/cars/concepts/360c?redirect=true (accessed 13 November 2020).

Wadud, Z., MacKenzie, D. and Leiby, P. (2016), "Help or hindrance? The travel, energy and carbon impacts of highly automated vehicles", Transportation Research Part A: Policy and Practice, Vol. 86, pp. 1-18. 10.1016/j.tra.2015.12.001.

Xavier Mosquet, Thomas Dauner, Nikolaus Lang, Michael Russmann, Antonella Mei-Pochtler, Rakshit Agrawal and Florian Schmieg (2015), "Revolution in the Driver's Seat: The Road to Autonomous Vehicles", The Boston Consulting Group. 